\title{
Study to Evaluate Stress Among Ophthalmic Surgeons with Different Levels of Surgical Experience
}

This article was published in the following Dove Press journal: Clinical Ophthalmology

\author{
Tejasvini Chandra (1) \\ Perwez Khan iD ${ }^{2}$ \\ Lubna Khan (iD) ${ }^{3}$ \\ 'Department of Ophthalmology, GSVM \\ Medical College and LLR Hospital, \\ Kanpur, India; ${ }^{2}$ Department of \\ Ophthalmology, GSVM Medical College \\ and LLR Hospital, Kanpur, India; \\ ${ }^{3}$ Department of Pathology, Department \\ of Transfusion Medicine, GSVM Medical \\ College and LLR Hospital, Kanpur, India
}

Correspondence: Perwez Khan

Warden Bungalow UG Girls Hostel, GSVM Medical College, Kanpur, UP, India Tel +9l 9451875355

Email perwezkhan@gmail.com
Aim: To assess and quantify the stress in two different groups of ophthalmic surgeons while performing cataract surgery.

Materials and Methods: This is a prospective observational institutional study. Healthy ophthalmic surgeons (4 trainee surgeons and 4 consultants) and 4 OT assistants without any history of systemic illness were studied while performing uncomplicated and uneventful cataract surgery. Resting state and post-operative (immediately after surgery) systolic blood pressure (SBP), diastolic blood pressure (DBP), pulse rate (PR), and oxygen saturation (SPO2) were measured by a Comen C80 multi-parameter monitor. Blood cortisol levels were measured by chemiluminescent assay (CLIA) and urine catecholamines levels (adrenaline, nor-adrenaline and dopamine) were measured by high performance liquid chromatography (HPLC). For assessment of stress among one group, paired $t$-test is used and for comparison of stress levels between trainee surgeons and consultants unpaired $t$-test is used. Results: Consultants performed phacoemulsification and trainee surgeons performed small incision cataract surgery. In both the groups, the post-operative values of SBP, DBP, PR, blood cortisol, and urine catecholamines were significantly higher than the pre-operative values. This difference was statistically significant. There was a significantly higher increase in SBP, DBP, PR, blood cortisol, urine adrenaline, and urine dopamine in trainee surgeons as compared to consultants whereas there was a significantly higher increase in urine noradrenaline in consultants as compared to trainee surgeons.

Conclusion: Our study reveals that every surgeon is under stress irrespective of experience though the level of stress is different among surgeons.

Keywords: urine catecholamines, blood cortisol

\section{Introduction}

Stress is an inevitable part of life. It is so common that it has become a way of life. Surgeons are more prone to stress and professional burnout, because they are responsible for human lives, and their actions - or lack of actions - can have a serious impact on their patients. ${ }^{1}$ Yet the effects of stress are seldom acknowledged and formal training to manage it is rarely offered. ${ }^{2}$ Surgical expertise is complex with varying predictable and unpredictable results. ${ }^{3}$ The performance of a surgeon determines the outcome of the procedure as surgery is a safety critical domain.

Research has primarily focused on the development and assessment of technical skills. Cognitive performance has received much less attention. Although, skills 
such as judgment, decision-making, communication, and ability to cope are central components of surgical expertise. $^{4,5}$ Stress affects cognitive processes involving memory, ${ }^{6}$ recall of knowledge, and attention. The ability to recognize and manage potentially deleterious levels of intraoperative stress is crucial for safe surgical practices. As observed by Balch et al in 2009, current estimates are that approximately $15 \%$ of all physicians will be impaired at some time in their careers and will be unable to meet professional responsibilities because of mental illness, alcoholism, or drug dependency. ${ }^{7}$ Increasing evidence suggests that physician burnout can adversely affect physicians' satisfaction with their work (Cooper et al), quality of medical care they provide, patient safety, and contribute to medical errors. ${ }^{8}$

Stress can help to improve performance by enhancing alertness, concentration, focus, and efficiency of actions. However, when stress is too high it is perceived as unhelpful and detrimental to various aspects of surgical performance., ${ }^{9,10}$

Stress is primarily a physical response. When stressed, the body thinks it is under attack and switches to 'fight or flight' mode, releasing a complex mix of hormones and chemicals such as adrenaline, cortisol, and norepinephrine, to prepare the body for physical action. ${ }^{11}$ Stress is a key for survival, but too much stress can be destructive. Daily occurrence of stress for months or years can weaken the immune system and cause high blood pressure, fatigue, depression, and even heart disorders. ${ }^{12}$

The human body is designed to handle small doses of stress, but it is not equipped to handle long-term, chronic stress without health consequences (Green et al). ${ }^{\mathbf{1 3}}$ Stress can affect all aspects of life, including emotions, behaviors, thinking ability (de Kloet), and physical health. ${ }^{14}$ No part of the body is immune.

Among all the surgeries, cataract surgery requires an instant result. Any flaws, errors or complications while performing surgery cannot be hidden from the patients. The evolution of modern cataract surgery with higher expectations of near perfect results has led to added stress to ophthalmic surgeons whether experienced or inexperienced. The present study was undertaken with the aim to acknowledge the presence of stress due to surgery among surgeons with different levels of experience and to quantify it.

\section{Materials and Methods}

A hospital based prospective observational study was conducted on two groups of surgeons. Group 1 comprised 4 consultant surgeons between the ages of 40-45 years who have performed more than 10,000 cataract surgeries in their career.

Group 2 comprised of 4 trainee resident doctors (trainee surgeons) in the age group of 27-33 years who had performed 200-300 cataract surgeries in their career.

Group 3 comprised of 4 OT assistants in the age group of 35-50 years who had assisted in more than 12,000 cataract surgeries in their career.

Each surgeon was tested while performing 10 uncomplicated cataract surgeries during a period of one year. All the participating surgeons and OT assistants were healthy without any history of any systemic illness (namely cardiac diseases, hypertension, anxiety, sleep disorders, diabetes, etc.). Informed consent was obtained from all the participants. The study and data accumulation were carried out with the approval from the Ethical committee, GSVM Medical College, Kanpur; reference no. 09/E.C./STD/0603-2019. All participants provided informed consent to participate in this study, and this study was conducted in accordance with the Declaration of Helsinki.

Patient and public involvement: it was not appropriate to involve patients or the public in the design, or conduct, or reporting, or dissemination plans of our research.

The systolic blood pressure (SBP) and diastolic blood pressure (DBP) were expressed in millimeters of mercury $(\mathrm{mmHg})$, pulse rate (PR) in beats per minute (bpm) and oxygen saturation (SPO2) in percentage (\%). Participants were measured at resting state when the surgeon was at rest on non-surgical days and post-operatively (immediately after the surgery) by Comen C 80 multi-parameter monitor.

Blood cortisol levels were measured at resting state and post-operatively (immediately after the surgery). A $2 \mathrm{~mL}$ blood sample was collected in a plain vial and levels were measured by chemiluminescent immunoassay (CLIA) and expressed in nmol/L. All the samples of blood cortisol were taken during the same time of the day to exclude the diurnal variation. The sample collected at the time on resting day (around $10.00 \mathrm{am}$ ) and the time of sample collection on the day of surgery was almost the same (with difference of not more than 5-10 minutes, around $10.10 \mathrm{am})$.

Urine catecholamines (adrenaline, nor-adrenaline and dopamine) levels were also measured at resting state and post-operatively (immediately after the surgery). $50 \mathrm{~mL}$ of random urine was collected and samples were measured by high performance liquid chromatography (HPLC). In order to minimize the error of volume due to random 
sampling, the urine catecholamines values were corrected with creatinine and expressed as urine catecholamines $(\mu \mathrm{g}) /$ urine creatinine $(\mathrm{g})$. Similarly, the sample collected at the time on the resting day and the time of sample collection on the day of surgery was almost same (with a difference of not more than 5-10 minutes).

For assessment and quantification of the resting state and post-op values of different parameters in the same group of surgeons a paired $t$-test is used while for comparison between trainee surgeons and consultants an unpaired $t$-test is used. The GraphPad In Stat 3 software program was used for statistical analysis. Value of $\alpha$ error for the study was $5 \%$. Power of the study was $80 \%$. For sample size calculation for this study the following formula was used-

$$
\begin{aligned}
& \text { Number of samples per group }\{\mathrm{n}\} \\
& =\frac{2 \mathrm{x}(\mathrm{Z}(1-\alpha / 2) \neg \mathrm{Z} \beta)^{2} \mathrm{x} \sigma^{2}}{\Delta^{2}}
\end{aligned}
$$

Where $\alpha=$ significance level; $\beta=$ power, probability of detecting a significant result; $\sigma=\mathrm{SD}$ of data; $\Delta=$ size of difference. $\mathrm{p}$ value of $<0.05$ was considered significant at $95 \%$ confidence interval.

\section{Results}

Consultants (Group 1) performed the phacoemulsification cataract surgery. The resting state SBP (112.83 \pm 2.06$)$ $\mathrm{mmHg}$, DBP (78.70 \pm 3.66$) \mathrm{mmHg}$, and PR (78.40 \pm 3.88$)$ bpm were significantly lower than the post-op SBP (131.93 \pm 5.2$) \mathrm{mmHg}$, DBP $(89.32 \pm 3.41) \mathrm{mmHg}$, and PR (101.78 \pm 5.19$)$ bpm. Similarly the resting state blood cortisol levels $(268.72 \pm 37.52) \mathrm{nmol} / \mathrm{L}$, urine adrenaline levels $(10.91$ $\pm 5.73) \mu \mathrm{g} / \mathrm{g}$, urine nor-adrenaline levels $(36.53 \pm 11.27) \mu \mathrm{g} / \mathrm{g}$, and urine dopamine levels (112.89 \pm 30.89$) \mu \mathrm{g} / \mathrm{g}$ were significantly lower than the post-op blood cortisol levels $(361.15 \pm 83.32) \mathrm{nmol} / \mathrm{L}$, urine adrenaline levels (13.39 \pm 8.4$)$ $\mu \mathrm{g} / \mathrm{g}$, urine nor-adrenaline levels $(88.19 \pm 11.0) \mu \mathrm{g} / \mathrm{g}$, and urine dopamine levels $(216.54 \pm 59.89) \mu \mathrm{g} / \mathrm{g}$. The difference between the resting state and post-op values of the different parameters mentioned above was statistically significant ( $p$ $<0.0001$ ) at $95 \%$ confidence interval as shown in Table 1. The resting state SPO2 value $(98.22 \pm 0.7) \%$ and post-op SPO2 value $(98.60 \pm 0.7) \%$ did not show much change. This difference was statistically not significant $(\mathrm{p}=0.101)$.

Trainee surgeons (Group 2) performed small incision cataract surgery (SICS). The resting state SBP (130.08 $\pm 2.8) \mathrm{mmHg}$, DBP $(83.15 \pm 4.91) \mathrm{mmHg}$, and PR (78.47 $\pm 3.58) \mathrm{bpm}$ were significantly lower than the post-op SBP (161.60 \pm 2.78$) \mathrm{mmHg}$, DBP (102.95 \pm 5.40$) \mathrm{mmHg}$, and PR (112.13 \pm 4.83$)$ bpm. Similarly the resting state blood cortisol levels $(265.13 \pm 57.93) \mathrm{nmol} / \mathrm{L}$, urine adrenaline levels $(8.08$ $\pm 2.08) \mu \mathrm{g} / \mathrm{g}$, urine nor-adrenaline levels $(30.40 \pm 6.59) \mu \mathrm{g} / \mathrm{g}$, and urine dopamine levels $(131.36 \pm 21.15) \mu \mathrm{g} / \mathrm{g}$ were significantly lower than the post-op blood cortisol levels (441.71 \pm 72.83$) \mathrm{nmol} / \mathrm{L}$, urine adrenaline levels $(32.72$ $\pm 5.05) \mu \mathrm{g} / \mathrm{g}$, urine nor-adrenaline levels $(48.89 \pm 3.39) \mu \mathrm{g} / \mathrm{g}$, and urine dopamine levels $(264.90 \pm 18.37) \mu \mathrm{g} / \mathrm{g}$. The difference between the resting state and post-op values of the different parameters mentioned above was statistically significant $(\mathrm{p}<0.0001)$ at 95\% confidence interval as shown in Table 2. The resting state SPO2 value $(98.3 \pm 0.8) \%$ and postop SPO2 value $(98.8 \pm 0.8) \%$ did not show much change. This difference was statistically not significant $(\mathrm{p}=0.168)$.

When the resting state values and the post-op values of different parameters were compared between the consultants and the trainee surgeons the following observations were made. There was a significantly higher increase $(\mathrm{p}<0.0001)$ among trainee surgeons in SBP $(31.52 \pm 3.85) \mathrm{mmHg}$, DBP (19.80 \pm 7.99$) \mathrm{mmHg}$, and PR (33.65 \pm 5.64$)$ bpm as compared to consultants SBP (19.10 \pm 5.83$) \mathrm{mmHg}$, DBP (10.62 \pm 4.08$)$ $\mathrm{mmHg}$, and PR (23.37 \pm 5.33$)$ bpm. There was also

Table I Comparison in Mean Levels of Parameters Among Consultants (Post-Op and Resting State) in Cataract Surgery

\begin{tabular}{|l|l|l|l|l|l|l|l|}
\hline \multirow{2}{*}{ In Consultants } & \multicolumn{2}{|l|}{ Post-Op (Immediately After Surgery) } & Confidence Interval & \multicolumn{2}{l|}{ Resting State } \\
\cline { 2 - 3 } & Mean & SD & & & Mean & SD & p value \\
\cline { 2 - 7 } & Interval \\
SBP & 131.93 & 5.20 & $130.31-133.54$ & 112.83 & 2.06 & $<0.0001$ & $112.19-113.46$ \\
DBP & 89.32 & 3.41 & $88.26-90.37$ & 78.70 & 3.66 & $<0.0001$ & $77.56-79.83$ \\
PR & 101.78 & 5.19 & $100.17-103.38$ & 78.40 & 3.80 & $<0.0001$ & $77.22-79.57$ \\
SPO2 & 98.60 & 0.74 & $98.37-98.82$ & 98.22 & 0.76 & 0.0101 & $97.98-98.45$ \\
Blood cortisol & 361.10 & 83.31 & $335.17-386.75$ & 268.68 & 37.51 & $<0.0001$ & $256.82-280.27$ \\
Urine adrenaline & 13.39 & 8.46 & $10.76-16.01$ & 10.91 & 5.73 & $<0.0001$ & $9.13-12.68$ \\
Urine nor-adrenaline & 88.19 & 11.00 & $84.78-91.59$ & 36.53 & 11.27 & $<0.0001$ & $33.03-40.02$ \\
Urine dopamine & 216.54 & 59.89 & $197.98-235.09$ & 112.89 & 30.89 & $<0.0001$ & $103.31-122.46$ \\
\hline
\end{tabular}


Table 2 Comparison in Mean Levels of Parameters Among Trainee Surgeons (Post-Op and Resting State) in Cataract Surgery

\begin{tabular}{|c|c|c|c|c|c|c|c|}
\hline \multirow[t]{2}{*}{ In Trainee Surgeons } & \multicolumn{2}{|c|}{$\begin{array}{l}\text { Post-Op (Immediately After } \\
\text { Surgery) }\end{array}$} & \multirow[t]{2}{*}{ Confidence Interval } & \multicolumn{3}{|c|}{ Resting State } & \multirow[t]{2}{*}{ Confidence Interval In } \\
\hline & Mean & SD & & Mean & SD & $P$ value & \\
\hline SBP & 161.60 & 2.78 & $160.73-162.46$ & 130.08 & 2.58 & $<0.000$ I & $129.28-130.87$ \\
\hline DBP & 102.95 & 5.40 & $101.27-104.62$ & 83.15 & 4.91 & $<0.0001$ & $81.81 .62-8484.684$ \\
\hline PR & 112.13 & 4.83 & $110.63-113.62$ & 78.47 & 3.58 & $<0.0001$ & $77.36-79.57$ \\
\hline SPO2 & 98.87 & 0.85 & $98.60-99.13$ & 98.32 & 0.82 & 0.0026 & $98.06-98.57$ \\
\hline Blood cortisol & $44 I .65$ & 72.82 & $419.03-464$ & 265.10 & 57.93 & $<0.0001$ & $246.89-283.03$ \\
\hline Urine adrenaline & 32.72 & 5.05 & $31.15-34.28$ & 8.08 & 2.08 & $<0.0001$ & $7.43-8.72$ \\
\hline Urine nor-adrenaline & 48.89 & 3.39 & $47.83-49.94$ & 30.40 & 6.59 & $<0.0001$ & $28228.35-32.44$ \\
\hline Urine dopamine & 264.90 & 18.37 & $259.20-270.59$ & 131.36 & 21.15 & $<0.000$ I & $|24.80-137.9|$ \\
\hline
\end{tabular}

a significantly higher increase $(\mathrm{p}<0.0001)$ among trainee surgeons in blood cortisol levels $(176 \pm 9.10) \mathrm{nmol} / \mathrm{L}$, urine adrenaline levels $(24.64 \pm 5.21) \mu \mathrm{g} / \mathrm{g}$, and urine dopamine levels $(133.55 \pm 30.94) \mu \mathrm{g} / \mathrm{g}$ as compared to consultants blood cortisol levels $(92.15 \pm 8.55) \mathrm{nmol} / \mathrm{L}$, urine adrenaline levels $(2.48 \pm 0.30) \mu \mathrm{g} / \mathrm{g}$, and urine dopamine levels (130.65 $\pm 72.03) \mu \mathrm{g} / \mathrm{g}$. There was a significantly higher increase $(\mathrm{p}<0.0001)$ in urine nor-adrenaline levels among consultants $(51.66 \pm 15.41) \mu \mathrm{g} / \mathrm{g}$ as compared to trainee surgeons (18.48 $\pm 6.56) \mu \mathrm{g} / \mathrm{g}$ as shown in Figure 1. This difference between trainee surgeons and consultants for different parameters was statistically significant. There was no change in the levels of SPO2 among trainee surgeons $(0.52 \pm 0.01) \%$ as compared to consultants $(0.37 \pm 0.01) \%$. This difference was statistically not significant $(\mathrm{p}=0.235)$.

OT assistants assisted during the cataract surgeries performed by the consultants and trainee surgeons. The post-op values of SBP $(123.41 \pm 6.89) \mathrm{mmHg}$, DBP $(82.36 \pm 4.56)$ mmHg, PR (84.52 \pm 3.48$)$, SPO2 (99.26 \pm 0.73$) \%$, blood cortisol $(260.96 \pm 58.48) \mathrm{nmol} / \mathrm{l}$, urine adrenaline $(10.47 \pm 4.88) \mu \mathrm{g} /$ $\mathrm{g}$, urine nor-adrenaline $(35.53 \pm 12.62) \mu \mathrm{g} / \mathrm{g}$, and urine dopamine $(108.46 \pm 50.16) \mu \mathrm{g} / \mathrm{g}$ were only slightly higher than the resting state values of SBP $(120.36 \pm 7.42) \mathrm{mmHg}$, DBP (80.62 $\pm 5.71) \mathrm{mmHg}$, PR (82.46 \pm 6.82$),$ SPO2 (99.18 \pm 0.71$) \%$, blood cortisol (231.17 \pm 84.96$) \mathrm{nmol} / \mathrm{l}$, urine adrenaline $(8.77 \pm 3.24)$ $\mu \mathrm{g} / \mathrm{g}$, urine nor-adrenaline $(32.33 \pm 13.42) \mu \mathrm{g} / \mathrm{g}$, and urine dopamine $(97.62 \pm 44.42) \mu \mathrm{g} / \mathrm{g}$. The difference between the post-op and resting state values were statistically not significant $(\mathrm{p}>0.05)$.

\section{Discussion}

The study reveals that every surgeon is under stress irrespective of experience though the level of stress is different among surgeons. The psychological stress was greater among trainee

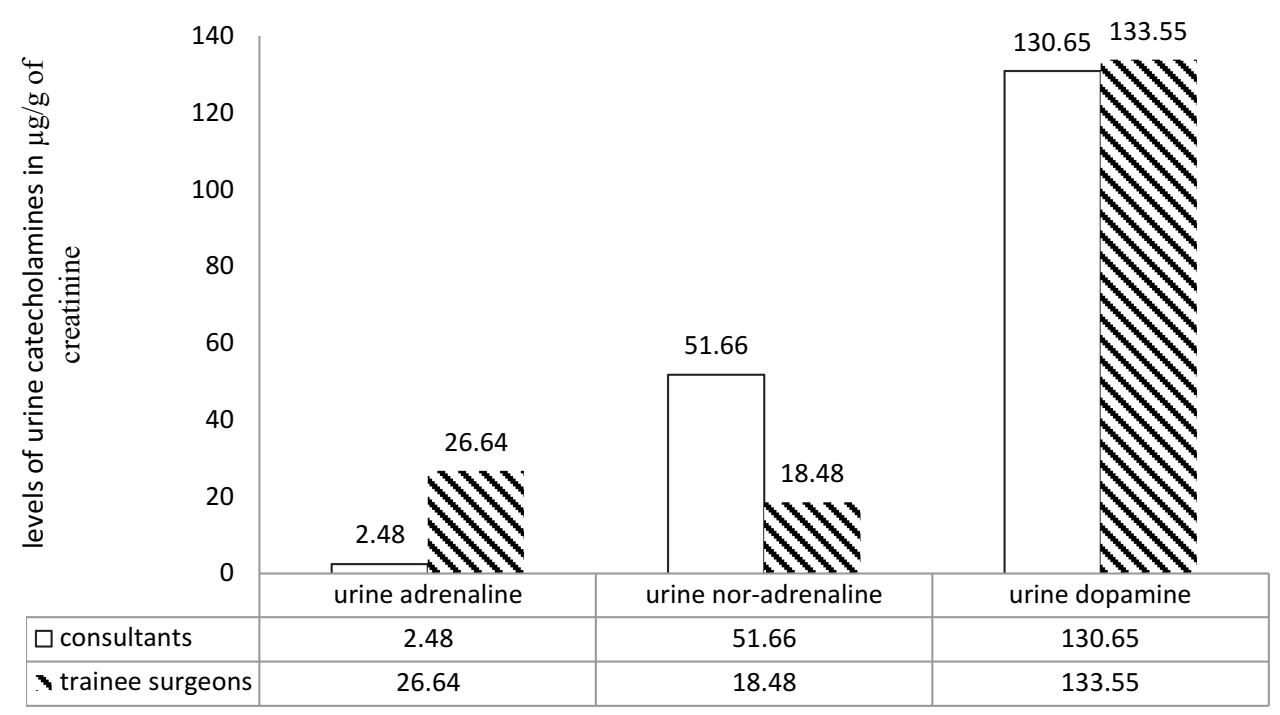

Figure I Comparison of mean change in levels of urine catecholamines (adrenaline, nor-adrenaline and dopamine) between consultants and trainee surgeons. 
surgeons than those in the experienced consultants because intraoperative stress decreases with experience.

Adrenaline, along with nor-adrenaline, is largely responsible for the immediate reactions when we are under stress. Adrenaline, when released, causes tensing of muscles, fast breathing, increase in heart rate, and also gives a surge of energy which we need to run away from a dangerous situation and also focuses the attention. ${ }^{15}$

Nor-adrenaline's primary role is arousal. Noradrenaline makes us more aware, awake, focused and more responsive, and speeds reaction time. It has been shown to play a role in a person's mood and ability to concentrate. It also makes blood vessels narrower, increasing blood pressure. ${ }^{16}$

Trainee surgeons showed a significantly higher increase in most of the parameters as compared to that of consultants except urine nor-adrenaline levels which showed a significantly higher increase in consultants. This indicates that consultants are more focused, alert and aroused during the intraoperative period whereas urine adrenaline levels showed a higher increase in trainee surgeons which indicates that they are more anxious and afraid during the intraoperative period, which causes the body to release a flood of adrenaline. ${ }^{17}$

Dopamine is a motivation molecule that helps us to get going. It also plays a role in mood, memory, more risk taking behavior, and is in charge of the brain's reward system $^{18}$. This stress hormone showed a higher increase in trainee surgeons as compared to consultants in our study which justifies the fact that trainee surgeons feel risk while operating and being rewarded when successful.

It was observed that the stress was also related to the length of the surgery. The consultants took less time to complete the surgery as compared to the trainee surgeons and all the parameters showed a higher increase in levels in trainee surgeons. Therefore the more time taken to complete the surgery, the greater the stress to the surgeon.

In comparison between the consultants and the OT assistants, the values between the post -op and resting state in consultants showed a significantly higher increase in post-op values whereas there was no significant change in the values of post-op and resting state in OT assistants who assisted the same surgeries performed by the consultants, which indicates that the stress was due to surgery per-se.

Ongoing stress for years and years can cause high levels of both adrenaline and nor-adrenaline. Having too much adrenaline and nor-adrenaline can cause high blood pressure, anxiety, excessive sweating, palpitations, headaches, sleep disorders, gastro-intestinal disorders (like irritable bowel syndrome), and many more disorders. ${ }^{19}$

Continuous big swings in blood pressure for a certain period of time (4-5 hrs) in a day while performing surgery and then going back to normal blood pressure for the rest of the day mimics a hypertensive state and causes deleterious effects on the body. Daily fluctuations in blood pressure is a leading contributor to heart attack, heart failure, and stroke. ${ }^{20}$. As the surgical span of surgeons is already short, being under constant stress can shorten it further.

For a surgeon, every surgery is a challenge and as a result they are under perennial stress, agitated, suffer from fatigue, and have early burnout. Often they are seen to be short-tempered and impatient. Work stress also leads to work/family conflict which then impacts life satisfaction.

The study helps to quantify the stress faced by surgeons and how increasing amounts of stress is deteriorating the health and well-being of the surgeons by initiating reactions inside the body which, if it lasts for a number of years, can cause serious damage to the health of the surgeon. Though the sample size in the study is small, still we were able to quantify stress and study the parameters related to it and provide useful information for future study. In our opinion, formal training to cope with stress should be an integral part of the surgeon's training programme. Meditation, yoga, music, outdoor and indoor games can be stress busters as per the individual's choice.

\section{Conclusion}

1. Every surgeon is under stress and stress decreases with experience as shown in our study.

2. Stress management is directly related to surgical performance and outcome and its introduction in surgical training curriculum will prove to be cost effective and beneficial for the patient.

3. Existence of stress was only hearsay, but this study helps to establish the existence of stress during surgery through physical and hormonal parameters and, once established, methods should be formulated to tackle it.

\section{Key Message}

Various physical and hormonal parameters showed changes because of stress while performing surgery. This increasing amount of stress affects the well-being and 
health of surgeons and methods to tackle it should be formulated.

\section{Limitation}

Sample size of the study is small.

\section{Funding}

This research received no specific grant from any funding agency in the public, commercial or not-for-profit sectors.

\section{Disclosure}

There are no competing interests for any author.

\section{References}

1. Campbell DA, Sonnad SS, Eckhauser FE, Campbell KK, Greenfield LJ. Burnout among American surgeons. Surgery. 2001;130(4):696-702. doi:10.1067/msy.2001.116676

2. Sexton JB, Thomas EJ, Helmreich RL. Error, stress, and teamwork in medicine and aviation: cross sectional surveys. BMJ. 2000;320 (7237):745-749. doi:10.1136/bmj.320.7237.745

3. Wetzel C, Kneebone RL, Woloshynowych M. The effects of stress on surgical performance. Am J Surg. 2006;191(1):5-10. doi:10.1016/j. amjsurg.2005.08.034

4. Hammermeister J, Burton D. Stress, appraisal, and coping revisited: examining the antecedents of competitive state anxiety with endurance athletes. Sport Psychol. 2001;15(1):66-90. doi:10.1123/ tsp.15.1.66

5. Helmreich RL, Wilhelm JA, Klinect JR, et al. Culture, error, and crew resource management. In: Salas E, Bowers CA, editors. Improving Teamwork in Organizations: Applications of Resource Management Training. Mahwah, NJ: Lawrence Erlbaum Associates; 2001:305-331.

6. McGaugh JL. Memory: a century of consolidation. Science. 2000;287 (5451):248. doi:10.1126/science.287.5451.248
7. Balch CM, Freischlag AJ, Shanafelt T. Stress and burnout among surgeons understanding and managing the syndrome and avoiding the adverse consequences. Arch Surg. 2009;144(4):371-376. doi:10.1001/archsurg.2008.575

8. Cooper CL, Rout U, Faragher B. Mental health, job satisfaction, and job stress among general practitioners. BMJ. 1989;298 (6670):366-370. doi:10.1136/bmj.298.6670.366

9. Helmreich RL. On error management: lessons from aviation. BMJ. 2000;320(7237):781-785. doi:10.1136/bmj.320.7237.781

10. Yule S. Critical thinking: non-technical skills in surgery. Surg News. 2005;3:75-76.

11. Elenkov IJ, Webster EL, Torpy DJ, Chrousos GP. Stress, corticotropin releasing hormone, glucocorticoids, and the immune/inflammatory response: acute and chronic effects. Ann N Y Acad Sci. 1999;876(1 NEUROENDOCRIN):1-13. doi:10.1111/j.1749-6632.1999.tb07618.x

12. Salleh MR. Life event, stress and illness. Malays J Med Sci. 2008;15 (4):9-18.

13. Green A, Duthie HL, Young HL, Peters TJ. Stress in surgeons. $\mathrm{Br}$ J Surg. 1990;77(10):1154-1158. doi:10.1002/bjs.1800771024

14. de Kloet ER. Stress in the brain. Eur J Pharmacol. 2000;405(1-3):187-198. doi:10.1016/S0014-2999(00)00552-5

15. Vedhara K, Hyde J, Gilchrist I, Tytherleigh M, Plummer S. Acute stress, memory, attention and cortisol. Psychoneuroendocrinology. 2000;25(6):535-549. doi:10.1016/S0306-4530(00)00008-1

16. Claude M, Sophie M, Antonini F, et al. Norepinephrine not too much, too long. Shock. 2015;44(4):305-309. doi:10.1097/SHK.0000000000000426

17. Yamamoto A, Hara T, Kikuchi K. Fujiwara T: intraoperative stress experienced by surgeons and assistants. Ophthalmic Surg Lasers. 1999;30(1):27-30.

18. Pruessner JC, Champagne F, Meaney MJ, Dagher A. Dopamine release in response to a psychological stress in humans and its relationship to early life maternal care: a positron emission tomography study using [11C] raclopride. $J$ Neurosci. 2004;24 (11):2825-2831. doi:10.1523/JNEUROSCI.3422-03.2004

19. Dimou FM, Eckelbarger D, Riall TS. Surgeon burn out: a systematic review. J Am Coll Surg. 2016;222(6):1230-1239. doi:10.1016/j. jamcollsurg.2016.03.022

20. Habib Y, Yunes P, Hedayat S, Thomas P, Amirhossein S. The impact of stress on body function: a review. Excli J. 2017;16:1057-1072.
Clinical Ophthalmology

\section{Publish your work in this journal}

Clinical Ophthalmology is an international, peer-reviewed journal covering all subspecialties within ophthalmology. Key topics include: Optometry; Visual science; Pharmacology and drug therapy in eye diseases; Basic Sciences; Primary and Secondary eye care; Patient Safety and Quality of Care Improvements. This journal is indexed on PubMed
Central and CAS, and is the official journal of The Society of Clinical Ophthalmology (SCO). The manuscript management system is completely online and includes a very quick and fair peer-review system, which is all easy to use. Visit http://www.dovepress.com/ testimonials.php to read real quotes from published authors.

\section{Dovepress}

